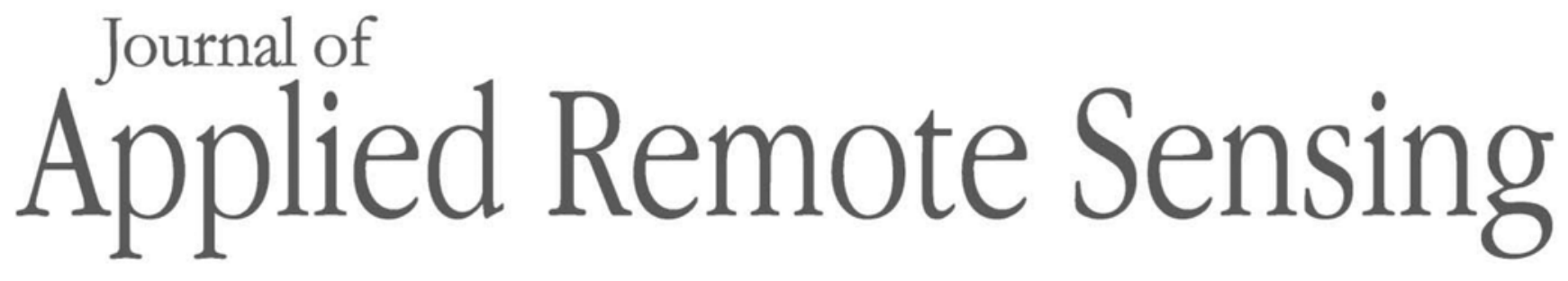

RemoteSensing.SPIEDigitalLibrary.org

\title{
Analytical study of seasonal variability in land surface temperature with normalized difference vegetation index, normalized difference water index, normalized difference built-up index, and normalized multiband drought index
}

Subhanil Guha

Himanshu Govil

Prabhat Diwan 


\title{
Analytical study of seasonal variability in land surface temperature with normalized difference vegetation index, normalized difference water index, normalized difference built-up index, and normalized multiband drought index
}

\author{
Subhanil Guha,* Himanshu Govil, and Prabhat Diwan \\ National Institute of Technology Raipur, Department of Applied Geology, Chhattisgarh, India
}

\begin{abstract}
Remote sensing technique often analyzes the thermal characteristics of any area. Our study focuses on estimating land surface temperature (LST) of Raipur City, emphasizing the urban heat island (UHI) and non-UHI inside the city boundary and the relationships of LST with four spectral indices (normalized difference vegetation index, normalized difference water index, normalized difference built-up index, and normalized multiband drought index). Mono-window algorithm is used as LST retrieval method on Landsat 8 Operational Land Imager (OLI) and Thermal Infrared Sensor (TIRS) data, which needs spectral radiance and emissivity of TIRS bands. The entire study is performed on 11 multidate Landsat 8 OLI and TIRS images taken from four different seasons; premonsoon, monsoon, postmonsoon, and winter, in a single-year time period. The Landsat 8 data derived LST is validated significantly with Moderate Resolution Imaging Spectroradiometer (MOD11A1) data. The results show that the UHI zones are mainly developed along the northern and southern portions of the city. The common area of UHI for four different seasons is developed mainly in the northwestern parts of the city, and the value of $\mathrm{LST}$ in the common UHI area varies from $26.45^{\circ} \mathrm{C}$ to $36.51^{\circ} \mathrm{C}$. Moreover, the strongest regression between LST and these spectral indices is observed in monsoon and postmonsoon seasons, whereas winter and premonsoon seasons revealed comparatively weak regression. The results also indicate that landscape heterogeneity reduces the reliability of the regression between LST with these spectral indices. (1) 2019 Society of Photo-Optical Instrumentation Engineers (SPIE) [DOI: 10.1117/1.JRS.13.024518]
\end{abstract}

Keywords: land surface temperature; normalized multiband drought index; normalized difference built-up index; normalized difference vegetation index; normalized difference water index; spectral indices; urban heat island.

Paper 180975 received Dec. 17, 2018; accepted for publication Apr. 17, 2019; published online May 13, 2019.

\section{Introduction}

Land surface temperature (LST) estimation is considered as one of the most significant tasks in thermal remote sensing study, where thermal impacts of changing land use/land cover (LULC) may regulate the generation of urban heat island (UHI) in mixed urban landscapes. ${ }^{1-5}$ The effect of UHI on some major cities (e.g., Beijing, Columbus, Shanghai, Baltimore, and Chicago) in the world is growing at an alarming rate and is directly related to the LULC categories. ${ }^{6-11}$ Various LULC indices (vegetation, impervious surface area, etc.) were applied in a UHI related remote sensing study to determine the changed pattern of LST in different types of natural and manmade landscape systems. ${ }^{12-16}$ Some recent articles discussed the statistical linear regression between LST and some selected LULC indices for separate study areas like Brisbane, ${ }^{17}$ Raipur, ${ }^{18}$ Shanghai, ${ }^{19}$ Addis Ababa, ${ }^{20}$ Mexico, ${ }^{21}$ Philadelphia, ${ }^{22}$ Florence, and Naples. ${ }^{23}$

A more recent direction includes the application of some sophisticated statistical techniques to estimate the seasonal variability of LST in the urban area. Cui and de Foy ${ }^{24}$ showed that

*Address all correspondence to Subhanil Guha, E-mail: subhanilguha@gmail.com

$1931-3195 / 2019 / \$ 25.00$ (C) 2019 SPIE 
vegetation cover, daytime insolation, and atmospheric stability are related to seasonal UHI variations in Mexico City, Mexico. Zhou et al. ${ }^{25}$ made an attempt in Baltimore, USA, to build relationships between land cover and UHI and their seasonal variability. Haashemi et al. ${ }^{26}$ presented a seasonal variability in the regression between LST and fractional vegetation cover, albedo, impervious surfaces, and elevation in Tehran, Iran.

In later studies, seasonal variation in the UHI effect was critically analyzed. Seasonal effects in urban thermal patterns were determined by spatial regression analyses in Ohio, USA. ${ }^{27}$ Multiple statistical methods were integrated to show the seasonal contrast of some LULC indices for LST distribution in Shenzhen, China. ${ }^{28}$ A seasonal variation in LST and selected LULC indices was investigated in Jaipur, India. ${ }^{29} \mathrm{~A}$ trend and seasonal decomposition model for LST change over Beijing, China, was investigated. ${ }^{30} \mathrm{~A}$ regression-based model was performed to determine the average annual and seasonal trend of LST in peninsular Spain. ${ }^{31,32}$ The relationship of urbanization and climate variability with urban and rural LST for 31 cities of China was critically investigated. ${ }^{33}$ An analytical research work performed in more than 86 major cities of China presented that UHI is seasonally different and is negatively related to the cloud cover percentage in transitional seasons.$^{34} \mathrm{~A}$ landscape source-sink distance index was applied to relate the landscape connectivity and LST variation in Beijing, China. ${ }^{35}$ A variation of LST due to elevation change in summer, winter, and monsoon season for Jaipur, India, was assessed. ${ }^{36}$ In summary, recent researchers tried to make a true attempt in the seasonal variability of LST in UHI of the major cities using common statistical methods.

This paper was an analytical study based on the seasonal variability of LST distribution inside the UHI and the area outside the UHI zones in a typical Indian city. The area outside the UHI zones is described here as non-UHI. ${ }^{18,23}$ Basically, the term "non-UHI" is slightly different from the term "urban cool island (UCI)." Generally, the term UCI indicates that the lowtemperature zones inside an urban area are characterized by urban vegetation, wetland, and water bodies, whereas the term "non-UHI" is used to present an area other than the UHI, which is actually denoted moderate-to low-temperature zones of an urban area. Hence, UCI can be considered as a part of non-UHI in an urban area. Another term "common-UHI" was used in this study to show the common area of UHI for each and every satellite image (total of 11 images) for four different seasons. ${ }^{18,23}$

Landsat TIR data are often used in the identification of UHI zones. ${ }^{37-39}$ LST derivation using Landsat TIR data becomes popular through the introduction of some algorithms, such as monowindow algorithm, ${ }^{40,41}$ single-channel algorithm, ${ }^{41-45}$ radiative transfer algorithm, ${ }^{41,45}$ split-window algorithm. ${ }^{41,45-47}$ Landsat 8 TIRS dataset has two TIR bands (bands 10 and 11). Generally, TIR band 10 is used for LST derivation as TIR band 11 is associated with larger uncertainties and thus it is not recommended to use the split-window algorithm. In the radiative transfer equation, LST estimation requires atmospheric correction and emissivity correction, which are difficult to perform. ${ }^{41}$ Ground emissivity, atmospheric transmittance, and effective mean atmospheric temperature are the parameters needed to derive the LST using mono-window algorithm, whereas single-channel algorithm needs atmospheric transmissivity, upwelling, and downwelling atmospheric radiance. Single-channel algorithm and mono-window algorithm both present significant results in LST retrieval. ${ }^{18,23,43,48}$ In this study, LST derivation process was conducted using the mono-window algorithm.

The specific aims of the study were: (1) to describe the nature of LST in the UHI, non-UHI, common UHI, and the whole of Raipur City for Landsat 8 OLI and TIRS images selected from premonsoon, monsoon, postmonsoon, and winter seasons in a single-year span and (2) to examine the variation in nature and strength of regression between LST and normalized difference vegetation index (NDVI), normalized difference water index (NDWI), normalized difference built-up index (NDBI), and normalized multiband drought index (NMDI) for the UHI, non-UHI, and common UHI and for the whole of Raipur City in these four particular aforesaid images.

\section{Study Area and Data}

Raipur, the capital city and the largest city of Chhattisgarh State in east-central India, located along the west of Mahanadi River, was selected for the present research work. Raipur is 
characterized by comparatively dry climate having no influence of coastal or maritime climatic condition. Moreover, Raipur is a rapidly growing city in India where a lot of new conversions of land have been seen in the recent time period. It has a wide variety in the population. The city has also seen exponential growth in industrial sectors and has emerged as a major business hub in central India. It is also ranked seventh in Ease of Living Index 2018 by Union Ministry of Housing and Urban Affairs. ${ }^{49}$ Raipur is considered to be one of the modern and smart technological cities in India due to the addition of new technology to the older system, power plant retrofit, home energy retrofit, seismic retrofit, eco-friendly, and sustainable nature; and thus the city was selected as the study area of the research work. Due to the presence of various types of surface materials, the nature of LST distribution is too dynamic. The latitudinal and longitudinal extents of Raipur City are $21^{\circ} 11^{\prime} 22^{\prime \prime} \mathrm{N}-21^{\circ} 20^{\prime} 02^{\prime \prime} \mathrm{N}$ and $81^{\circ} 32^{\prime} 20^{\prime \prime} \mathrm{E}-81^{\circ} 41^{\prime} 50^{\prime \prime} \mathrm{E}$, respectively (Fig. 1). The mean elevation of the city is around $298 \mathrm{~m}$. Raipur City is characterized by a tropical wet and dry climate. There are four seasons observed in Raipur according to the India Meteorological Department, i.e., premonsoon or summer (March to May), monsoon (June to September), postmonsoon (October to November), and winter (December to February). Generally, the summer months (March to May) remain hot and dry. The mean annual temperature of Raipur City lies between $21^{\circ} \mathrm{C}$ to $34^{\circ} \mathrm{C}$. Amount of rainfall is moderate (average annual rainfall is 120 to $150 \mathrm{~cm}$.). Rain occurs mainly in the monsoon season. At that time, vegetation was looking green and healthy, containing more chlorophyll component. In the rainy monsoon season, temperature falls at a significant rate from the summer or premonsoon season. A pleasant weather condition persists throughout the postmonsoon season. Winter season remains cool and dry. December is considered the coldest month (average temperature $12^{\circ} \mathrm{C}$ ) of the city.

A total of eleven (three from the premonsoon, two from the monsoon, three from the postmonsoon, and three from winter season) Landsat 8 Operational Land Imager (OLI) and Thermal Infrared Sensor (TIRS) data $(<10 \%$ cloud coverage) were selected to determine the UHI zones over all of Raipur City (Table 1). The Landsat 8 datasets were freely downloaded from the website of the United States Geological Survey. ${ }^{50}$ Only Landsat TIR band 10 data were

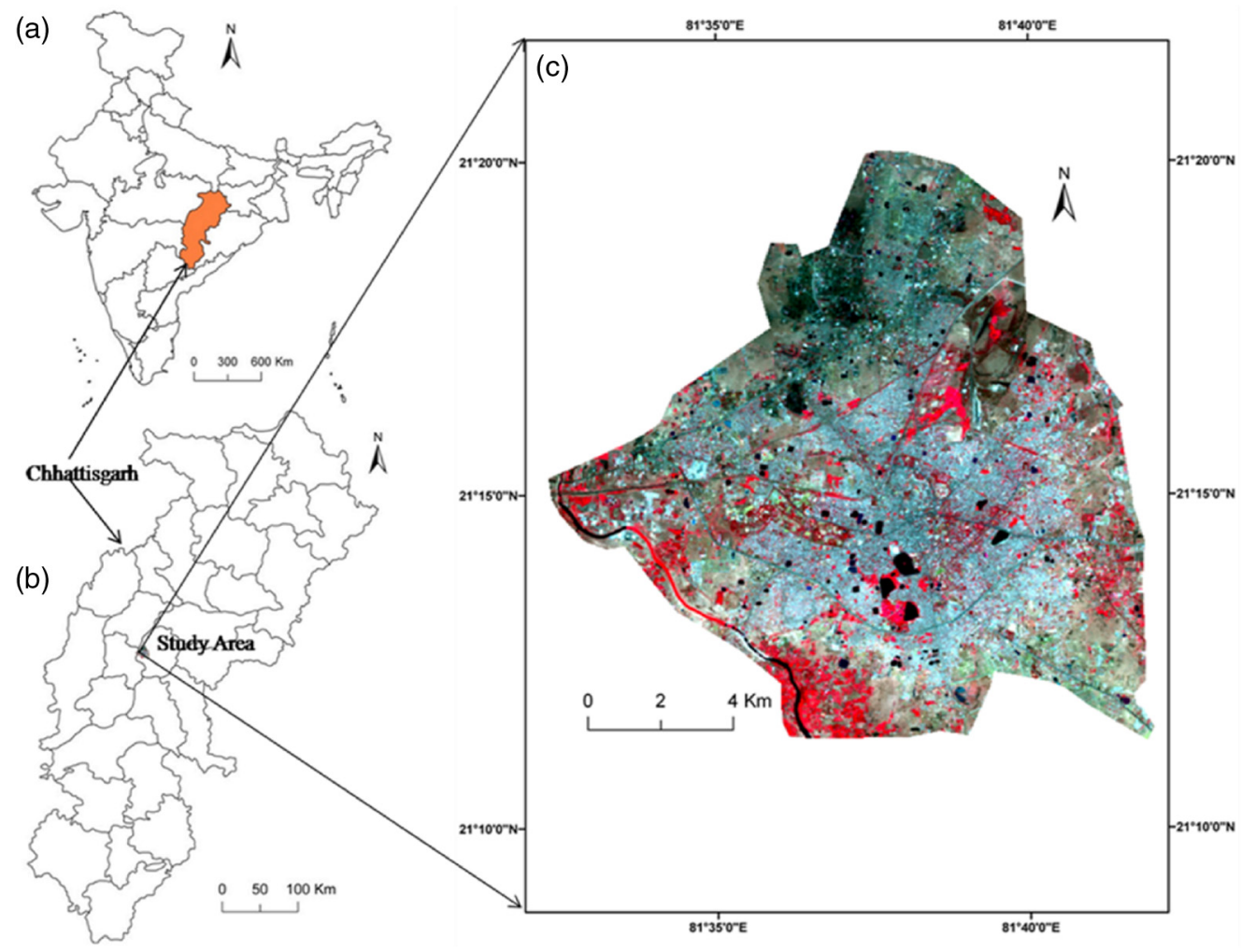

Fig. 1 The study area: (a) Chhattisgarh in India, (b) Raipur City in Chhattisgarh, and (c) Raipur City. 
Guha, Govil, and Diwan: Analytical study of seasonal variability in land surface...

Table 1 Specification of multidate Landsat $8 \mathrm{OLI}$ and TIRS satellite images.

\begin{tabular}{lccccccc}
\hline \hline & & & & $\begin{array}{c}\text { Sun } \\
\text { elevation } \\
\text { (deg) }\end{array}$ & $\begin{array}{c}\text { Sun } \\
\text { azimuth } \\
\text { (deg) }\end{array}$ & $\begin{array}{c}\text { Cloud } \\
\text { cover (\%) }\end{array}$ & $\begin{array}{c}\text { Earth-Sun } \\
\text { distance } \\
\text { (astronomical unit) }\end{array}$ \\
\hline 09-Nov-2013 & Postmonsoon & $14: 27: 51$ & $142 / 044$ & 47.1003 & 152.5147 & 0.03 & 0.9905 \\
25-Nov-2013 & Postmonsoon & $14: 27: 43$ & $142 / 044$ & 43.2895 & 153.9750 & 0.00 & 0.9871 \\
11-Dec-2013 & Winter & $14: 27: 42$ & $142 / 044$ & 40.6309 & 153.5245 & 0.00 & 0.9847 \\
27-Dec-2013 & Winter & $14: 27: 33$ & $142 / 044$ & 39.5066 & 151.6083 & 1.69 & 0.9835 \\
28-Jan-2014 & Winter & $14: 27: 13$ & $142 / 044$ & 42.3669 & 144.8623 & 0.49 & 0.9849 \\
17-Mar-2014 & Premonsoon & $14: 26: 36$ & $142 / 044$ & 55.9542 & 129.3872 & 0.00 & 0.9949 \\
02-Apr-2014 & Premonsoon & $14: 26: 19$ & $142 / 044$ & 60.9189 & 121.7216 & 0.00 & 0.9995 \\
20-May-2014 & Premonsoon & $14: 25: 38$ & $142 / 044$ & 68.5638 & 90.4085 & 5.46 & 1.0118 \\
05-Jun-2014 & Monsoon & $14: 25: 45$ & $142 / 044$ & 68.3821 & 83.3098 & 0.02 & 1.0146 \\
25-Sep-2014 & Monsoon & $14: 26: 11$ & $142 / 044$ & 59.2100 & 134.1804 & 0.81 & 1.0030 \\
12-Nov-2014 & Postmonsoon & $14: 26: 21$ & $142 / 044$ & 46.2266 & 152.4664 & 7.59 & 0.9899 \\
\hline \hline
\end{tabular}

used for LST retrieval process because TIR band 11 data faces some calibration uncertainty. Optical bands 3, 4, 5, 6, and 7 datasets were used in developing NDVI, NDWI, NDBI, and NMDI. The entire study was performed in the environment of some sophisticated image processing and GIS software packages.

\section{Methodology}

\subsection{Determination of NDVI, NDWI, NDBI, and NMDI}

$\mathrm{NDVI}^{51}$ is considered one of the most frequently used vegetation indices in remote sensing study. It is also applied in deriving LST and normally shows a negative regression with LST. NDWI ${ }^{52}$ is generally used for water body extraction. $\mathrm{NDBI}^{53}$ is another spectral index, which was applied in this study for built-up area extraction. $\mathrm{NMDI}^{54}$ was also used to extract the dry soil or bare land. The formulation of these four spectral indices was presented in Table 2. Integration of suitable threshold values of these spectral indices is useful in identifying several LULC types. ${ }^{55}$

\subsection{LST Derivation Using Landsat 8 OLI and TIRS Band}

For retrieving LST using mono-window algorithm, the original Landsat 8 TIR band (100-m resolution) was resampled into $30 \mathrm{~m}$. The entire procedure included the following equations: ${ }^{56}$

Table 2 Description of NDVI, NDWI, NDBI, and NMDI.

\begin{tabular}{lccr}
\hline \hline Acronym & Description & Formulation & Reference \\
\hline $\mathrm{NDVI}$ & Normalized difference vegetation index & NIR-Red & 51 \\
$\mathrm{NDWI}$ & Normalized difference water index & Green-NIR & 52 \\
$\mathrm{NDBI}$ & Normalized difference built-up index & SWIR1-NIR & 53 \\
$\mathrm{NMDI}$ & Normalized multiband difference index & SWIR1+NIR & [NIR-(SWIR1+SWIR2)] \\
\hline \hline
\end{tabular}




$$
L_{\lambda}=0.0003342 \times D N+0.1
$$

where $L_{\lambda}$ is spectral radiance $\left(\mathrm{Wm}^{-2} \mathrm{sr}^{-1} \mathrm{~mm}^{-1}\right)$

$$
T_{b}=\frac{K_{2}}{\ln \left(\frac{K_{1}}{L_{\lambda}}+1\right)},
$$

where $T_{b}$ is the at-sensor brightness temperature $(\mathrm{K}),{ }^{57} K_{2}$ and $K_{1}$ are the calibration constants. Here $K_{1}$ is $774.89\left(\mathrm{Wm}^{-2} \mathrm{sr}^{-1} \mathrm{~mm}^{-1}\right)$ and $K_{2}$ is $1321.08\left(\mathrm{Wm}^{-2} \mathrm{sr}^{-1} \mathrm{~mm}^{-1}\right)$

$$
F_{v}=\left(\frac{\mathrm{NDVI}-\mathrm{NDVI}_{\min }}{\mathrm{NDVI}_{\max }-\mathrm{NDVI}_{\min }}\right)^{2}
$$

where $\mathrm{NDVI}_{\min }$ is the minimum value (0.2) of NDVI for bare soil pixel and $\mathrm{NDVI}_{\max }$ is the maximum value $(0.5)$ of NDVI for healthy vegetation pixel. ${ }^{58-60}$

$d \varepsilon$ is the geometric distribution effect for the natural surface and internal reflection. The value of $d \varepsilon$ may be $2 \%$ for mixed and elevated land surfaces ${ }^{58}$

$$
d \varepsilon=\left(1-\varepsilon_{s}\right)\left(1-F_{v}\right) F \varepsilon_{v}
$$

where $\varepsilon_{s}$ is the soil emissivity, $F v$ is the fractional vegetation, $F$ is a shape factor $(0.55),{ }^{58}$ and $\varepsilon_{v}$ is the vegetation emissivity

$$
\varepsilon=\varepsilon_{v} F_{v}+\varepsilon_{s}\left(1-F_{v}\right)+d \varepsilon,
$$

where $\varepsilon$ is land surface emissivity. The value of $\varepsilon$ is determined by the following equation: ${ }^{58}$

$$
\varepsilon=0.004 \times F_{v}+0.986 .
$$

Water vapour content is determined by the following equation: ${ }^{61}$

$$
w=0.0981 \times\left\{10 \times 0.6108 \times \exp \left[\frac{17.27 \times\left(T_{0}-273.15\right)}{237.3+\left(T_{0}-273.15\right)}\right] \times \mathrm{RH}\right\}+0.1697,
$$

where $w$ is the water vapor content $\left(\mathrm{g} / \mathrm{cm}^{2}\right), T_{0}$ is the near-surface air temperature $(\mathrm{K})$, and $\mathrm{RH}$ is the relative humidity $(\%)$. These parameters of the atmospheric profile were the average values of 14 stations around Raipur, which were obtained from the Meteorological Centre, Raipur and the Regional Meteorological Centre, Nagpur.

$$
\tau=1.031412-0.11536 w,
$$

where $\tau$ is the total atmospheric transmittance. ${ }^{62}$

Raipur City is located in a tropical region. Thus the following equations were applied to compute the effective mean atmospheric transmittance of Raipur:

$$
\begin{gathered}
T_{a}=17.9769+0.91715 T_{0}, \\
T_{s}=\frac{\left\{a(1-C-D)+[b(1-C-D)+C+D] T_{b}-D T_{a}\right\}}{C}, \\
C=\varepsilon \tau, \\
D=(1-\tau)[1+(1-\varepsilon) \tau],
\end{gathered}
$$

where $T_{a}$ is the mean atmospheric temperature, $T_{s}$ is the LST, $a=-67.355351$, and $b=0.458606$. 


\subsection{Mapping UHI and Non-UHI Inside a City Area}

UHI and non-UHI zones were demarcated using the following methods: ${ }^{18,23}$

$$
\begin{gathered}
\mathrm{LST}>\mu+0.5 * \sigma, \\
0<\mathrm{LST} \leq \mu+0.5 * \sigma,
\end{gathered}
$$

where $\mu$ and $\sigma$ are the mean and standard deviation values of LST for the whole area of the city.

\section{Results and Discussion}

\subsection{Variation in the Distribution of NDVI, NDWI, NDBI, and NMDI}

The descriptive statistics (Table 3) were presented the reliable nature of NDVI, NDWI, NDBI, and NMDI (Fig. 2) for the whole of Raipur City. The highest mean NDVI value (0.1468) was found in the monsoon season. Premonsoon season reflected the minimum value $(-0.1466)$ of mean NDWI. The lowest mean value $(-0.0569)$ of NDBI was observed in the postmonsoon season. The highest $(-0.2743)$ mean NMDI was found in premonsoon season and the lowest $(-0.2866)$ mean NMDI value was found in winter. In the winter season, all the four indices had the least value of standard deviation.

Table 3 Descriptive statistics of NDVI, NDWI, NDBI, and NMDI for the whole of Raipur City in four

\begin{tabular}{|c|c|c|c|c|}
\hline Season & Min & $\operatorname{Max}$ & Mean & Standard deviation \\
\hline \multicolumn{5}{|l|}{ NDVI values } \\
\hline Premonsoon (mean) & -0.1082 & 0.4702 & 0.1428 & 0.0645 \\
\hline Monsoon (mean) & -0.1089 & 0.4664 & 0.1468 & 0.0635 \\
\hline Postmonsoon (mean) & -0.1025 & 0.4183 & 0.1392 & 0.0659 \\
\hline Winter (mean) & -0.1265 & 0.4284 & 0.0954 & 0.0561 \\
\hline \multicolumn{5}{|l|}{ NDWI values } \\
\hline Premonsoon (mean) & -0.4112 & 0.1514 & -0.1426 & 0.0576 \\
\hline Monsoon (mean) & -0.4102 & 0.1434 & -0.1466 & 0.0564 \\
\hline Postmonsoon (mean) & -0.3596 & 0.1371 & -0.1192 & 0.0602 \\
\hline Winter (mean) & -0.4006 & 0.1582 & -0.0877 & 0.0398 \\
\hline \multicolumn{5}{|l|}{ NDBI values } \\
\hline Premonsoon (mean) & -0.3195 & 0.1668 & -0.0198 & 0.0474 \\
\hline Monsoon (mean) & -0.3219 & 0.2373 & -0.0158 & 0.0477 \\
\hline Postmonsoon (mean) & -0.3153 & 0.1754 & -0.0569 & 0.0426 \\
\hline Winter (mean) & -0.3508 & 0.1857 & -0.0199 & 0.0374 \\
\hline \multicolumn{5}{|l|}{ NMDI values } \\
\hline Premonsoon (mean) & -0.4635 & 0.0773 & -0.2743 & 0.0518 \\
\hline Monsoon (mean) & -0.5483 & 0.0714 & -0.2761 & 0.0511 \\
\hline Postmonsoon (mean) & -0.5361 & 0.0602 & -0.2385 & 0.0499 \\
\hline Winter (mean) & -0.5946 & 0.0958 & -0.2866 & 0.0398 \\
\hline
\end{tabular}
seasons. 

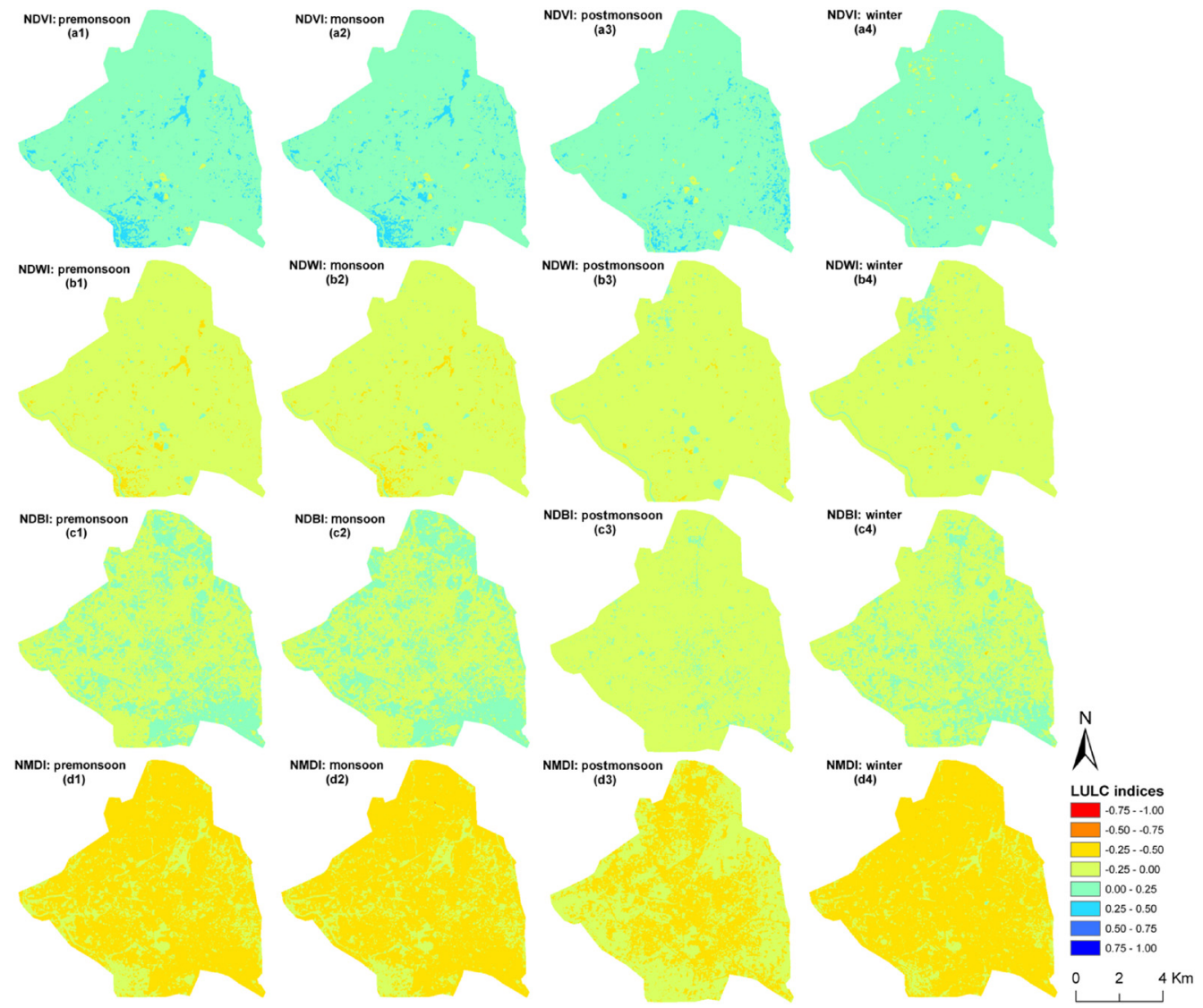

Fig. 2 Seasonal variations of NDVI, NDWI, NDBI, and NMDI values in the whole of Raipur City: (a) premonsoon, (b) monsoon, (c) postmonsoon, and (d) winter.

\subsection{Variation of LST Distribution}

The LST maps retrieved from satellite image were shown in Fig. 3. Seasonal variation in the LST distribution showed a specific thermal pattern. The mean LST values in the premonsoon, monsoon, postmonsoon, and winter seasons were $34.40^{\circ} \mathrm{C}, 31.70^{\circ} \mathrm{C}, 25.22^{\circ} \mathrm{C}$, and $24.71^{\circ} \mathrm{C}$, respectively. The ranges of temperature (maximum temperature-minimum temperature) were found as $12.71^{\circ} \mathrm{C}$ in premonsoon image, $10.20^{\circ} \mathrm{C}$ in monsoon image, $8.81^{\circ} \mathrm{C}$ in the postmonsoon image, and $10.03^{\circ} \mathrm{C}$ in the winter image, respectively. For UHI zones of the study area, the highest threshold LST $\left(35.23^{\circ} \mathrm{C}\right)$ was observed in the premonsoon season. Postmonsoon season reflected the least standard deviation value $\left(1.06^{\circ} \mathrm{C}\right)$ of LST (Table 4$)$. Basically, this type of LST variation was noticed due to the change in vegetation abundance and soil moisture content. Monsoon and postmonsoon seasons were characterized by healthy vegetation and wet soil.

\subsection{LST Validation with Respect to MODIS Satellite Sensor}

A validation of retrieved LST using Landsat 8 data with in situ measurement or with any other satellite data is mandatory to conduct any kind of further analysis. Due to the unavailability of in situ measurement, Moderate Resolution Imaging Spectroradiometer (MODIS) satellite data were applied as a reference image for the validation of LST retrieved from Landsat 8 data. The MODIS LST daily product is derived from bands 31 and 32 by the emissivity of land cover types, atmospheric column water vapor, and lower boundary air surface temperature. ${ }^{63,64}$

Landsat and MODIS sensors could not provide images of the same study area for any particular date. Thus the acquisition dates of MODIS data were either one day before or one day after the acquisition dates of Landsat 8 data. A total of eleven (three from the premonsoon season, two from the monsoon season, three from the postmonsoon season, and three from winter season) MOD11A1 data were taken for the validation of estimated LST using Landsat 8 data. 

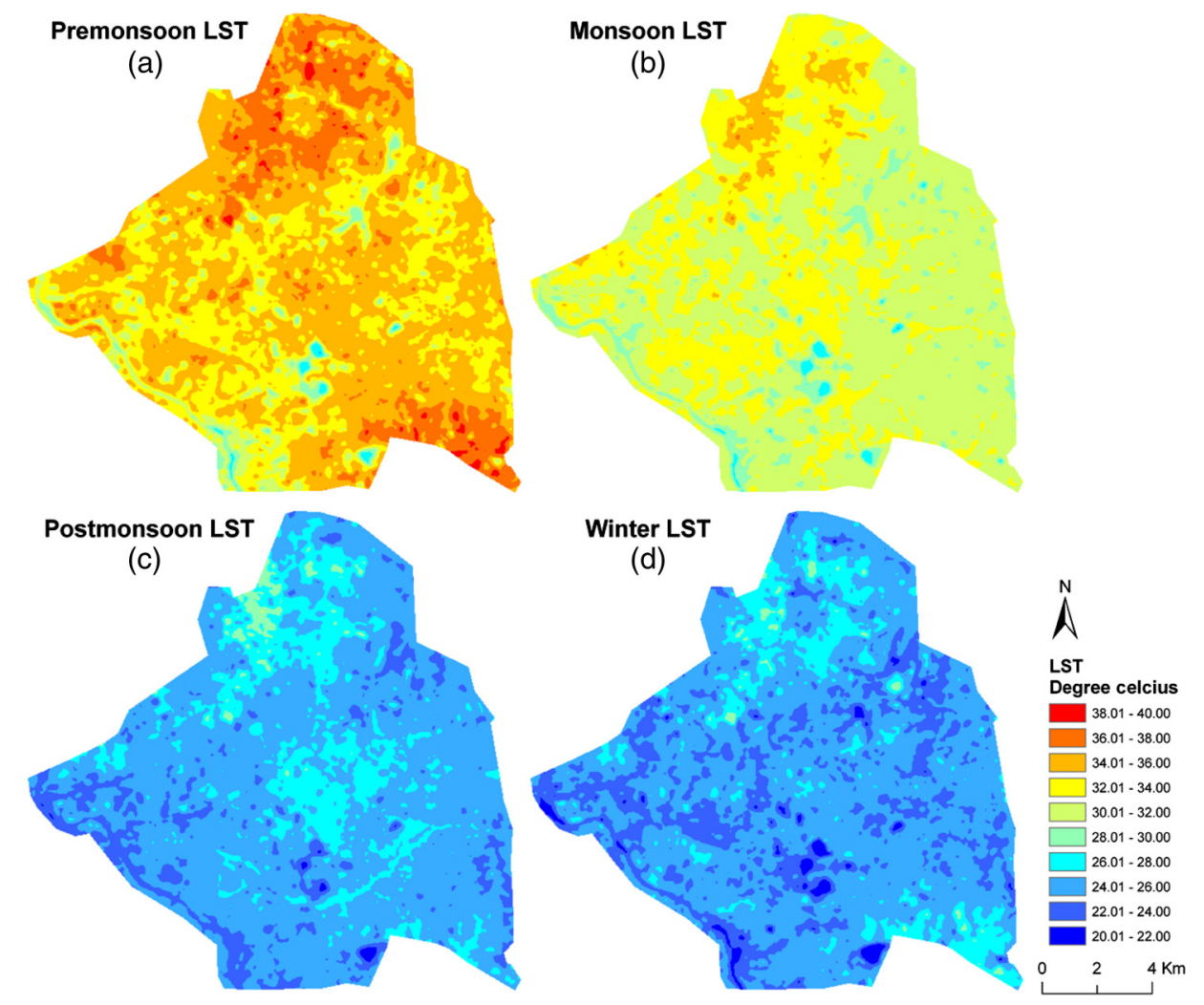

Fig. 3 Seasonal variations in LST maps of Raipur City: (a) premonsoon, (b) monsoon, (c) postmonsoon, and (d) winter.

Table 4 Seasonal variations in spatial distribution of LST $\left({ }^{\circ} \mathrm{C}\right)$ for the whole of Raipur City.

\begin{tabular}{lccccc}
\hline \hline Season & $\begin{array}{c}\text { LST } \\
\text { (minimum) }\end{array}$ & $\begin{array}{c}\text { LST } \\
\text { (maximum) }\end{array}$ & $\begin{array}{c}\text { LST } \\
\text { (mean) }\end{array}$ & $\begin{array}{c}\text { LST (standard } \\
\text { deviation) }\end{array}$ & $\begin{array}{c}\text { Threshold LST } \\
\text { for UHI }\end{array}$ \\
\hline Premonsoon (mean) & 26.97 & 39.68 & 34.40 & 1.65 & 35.23 \\
Monsoon (mean) & 26.43 & 36.63 & 31.70 & 1.16 & 32.28 \\
Postmonsoon (mean) & 21.53 & 30.34 & 25.22 & 1.06 & 25.75 \\
Winter (mean) & 20.12 & 30.15 & 24.71 & 1.15 & 25.29 \\
\hline \hline
\end{tabular}

No such atmospheric disturbances were noticed in the acquisition dates of the selected satellite images for both the sensors. For MOD11A1 and Landsat 8 data, the spatial resolution of retrieved LST was 1000 and $100 \mathrm{~m}$, respectively. Therefore, before integrating the data, 1000-m pixel size was resampled into 100-m pixel size (Fig. 4). There was found a small difference between Landsat derived mean LST and the corresponding MODIS derived mean LST values due to (a) 30 min intervals between the Landsat 8 and MODIS sensors (b) water vapor content, and (c) scale effect in resampling method. ${ }^{63}$ Figure 4 compared four Landsat 8 data derived LST images with the four corresponding MODIS LST images for four different seasons.

For the validation of the results, the pixel-wise regression analysis method was applied between Landsat 8 retrieved LST values and the corresponding MODIS retrieved LST values. Significant positive correlation coefficients $(0.70$ for the premonsoon, 0.75 for the monsoon, 0.69 for the postmonsoon, and 0.59 for winter) were found between Landsat 8 data derived LST and MODIS data derived LST (Table 5). Hence, it can be said that the results were reliable and consistent in spite of lacking some LST retrieval parameters. 


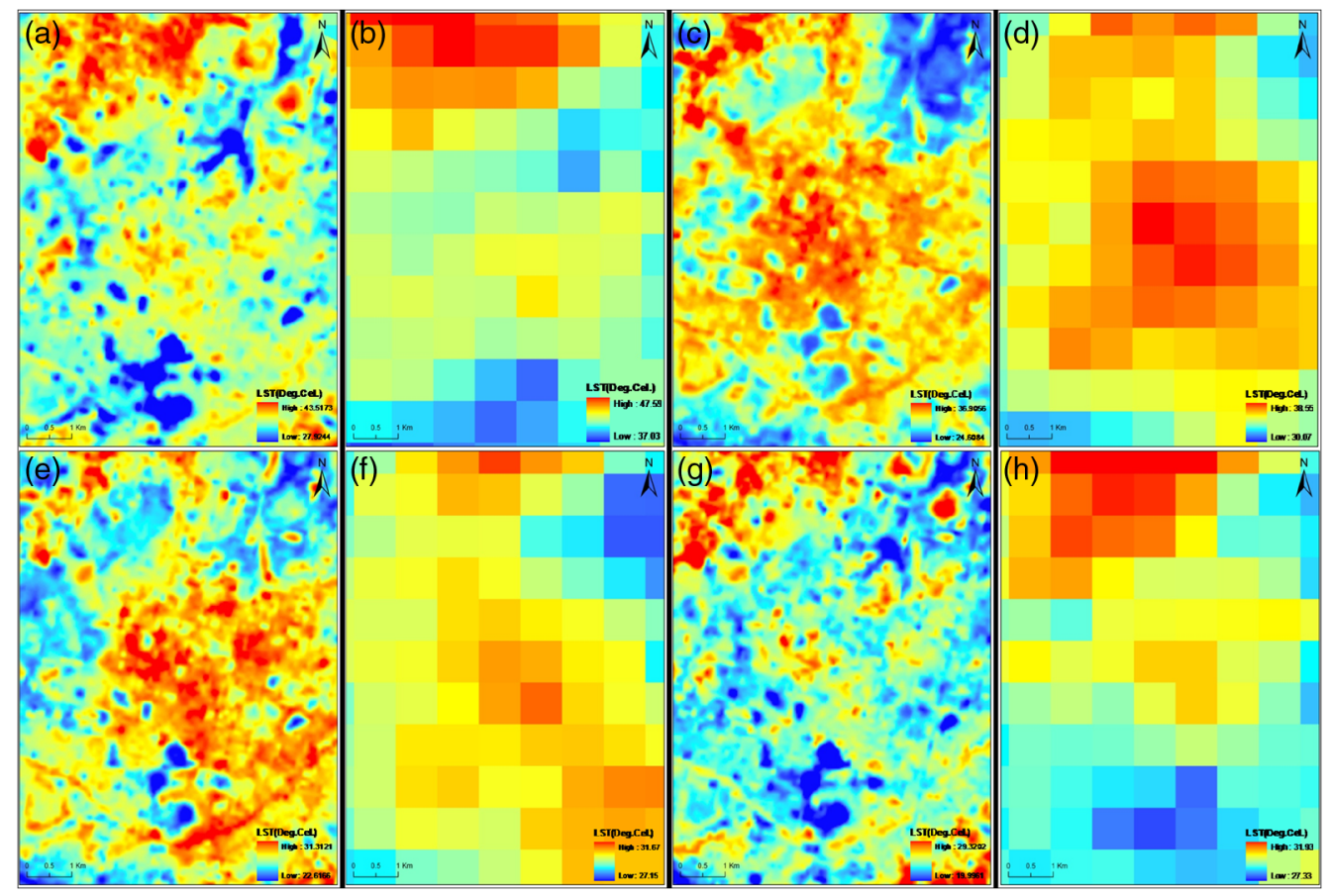

Fig. 4 Retrieved LST from Landsat 8 data and MODIS data: (a) 02-Apr-2014 (Landsat 8), (b) 03Apr-2014 (MODIS), (c) 25-Sep-2014 (Landsat 8), (d) 24-Sep-2014 (MODIS), (e) 09-Nov-2013 (Landsat 8), (f) 08-Nov-2013 (MODIS), (g) 27-Dec-2013 (Landsat 8), and (h) 28-Dec-2013 (MODIS).

Table 5 Validation of LST retrieved from Landsat 8 data with MODIS data in different dates of acquisition.

\begin{tabular}{llc}
\hline \hline Landsat 8 data & MODIS data & Correlation coefficient \\
\hline 09-Nov-2013 & 08-Nov-2013 & 0.69 \\
$25-N o v-2013$ & $26-N o v-2013$ & 0.66 \\
11-Dec-2013 & 12-Dec-2013 & 0.61 \\
27-Dec-2013 & 28-Dec-2013 & 0.68 \\
28-Jan-2014 & 27-Jan-2014 & 0.45 \\
17-Mar-2014 & 18-Mar-2014 & 0.74 \\
02-Apr-2014 & 03-Apr-2014 & 0.68 \\
20-May-2014 & 21-May-2014 & 0.68 \\
05-Jun-2014 & 04-Jun-2014 & 0.73 \\
25-Sep-2014 & 24-Sep-2014 & 0.77 \\
12-Nov-2014 & 13-Nov-2014 & 0.71 \\
Premonsoon (mean) & & 0.70 \\
Monsoon (mean) & & 0.75 \\
Postmonsoon (mean) & & 0.69 \\
Winter (mean) & & 0.59 \\
\hline \hline
\end{tabular}


Table 6 Seasonal variations in LST $\left({ }^{\circ} \mathrm{C}\right)$ of UHI, non-UHI, and common UHI in Raipur City.

\begin{tabular}{|c|c|c|c|c|c|c|c|c|c|c|c|c|}
\hline \multirow[b]{2}{*}{ Season } & \multicolumn{3}{|c|}{ LST (minimum) } & \multicolumn{3}{|c|}{ LST (maximum) } & \multicolumn{3}{|c|}{ LST (mean) } & \multicolumn{3}{|c|}{$\begin{array}{l}\text { LST (standard } \\
\text { deviation) }\end{array}$} \\
\hline & UHI & $\begin{array}{l}\text { Non- } \\
\text { UHI }\end{array}$ & $\begin{array}{l}\text { Common } \\
\text { UHI }\end{array}$ & UHI & $\begin{array}{l}\text { Non- } \\
\text { UHI }\end{array}$ & $\begin{array}{c}\text { Common } \\
\text { UHI }\end{array}$ & UHI & $\begin{array}{l}\text { Non- } \\
\text { UHI }\end{array}$ & $\begin{array}{c}\text { Common } \\
\text { UHI }\end{array}$ & UHI & $\begin{array}{l}\text { Non- } \\
\text { UHI }\end{array}$ & $\begin{array}{c}\text { Common } \\
\text { UHI }\end{array}$ \\
\hline $\begin{array}{l}\text { Premonsoon } \\
\text { (mean) }\end{array}$ & 35.23 & 26.97 & 35.23 & 39.68 & 35.23 & 39.68 & 36.23 & 33.69 & 36.51 & 0.78 & 1.32 & 0.78 \\
\hline $\begin{array}{l}\text { Monsoon } \\
\text { (mean) }\end{array}$ & 32.28 & 26.43 & 32.28 & 36.63 & 32.28 & 36.63 & 33.07 & 31.20 & 33.57 & 0.76 & 0.83 & 0.81 \\
\hline $\begin{array}{l}\text { Postmonsoon } \\
\text { (mean) }\end{array}$ & 25.75 & 21.53 & 25.75 & 30.34 & 25.75 & 30.34 & 26.49 & 24.73 & 26.99 & 0.71 & 0.70 & 0.79 \\
\hline $\begin{array}{l}\text { Winter } \\
\text { (mean) }\end{array}$ & 25.29 & 20.12 & 25.29 & 30.15 & 25.29 & 30.15 & 26.17 & 24.21 & 26.45 & 0.76 & 0.78 & 0.78 \\
\hline
\end{tabular}

\subsection{UHI, Non-UHI, and Common UHI of the Study Area}

The UHI intensity (difference between the mean LST of UHI and the mean LST of non-UHI) of the study area was determined in Table 6. In premonsoon and winter seasons, the UHI zones were mainly generated in the north, west, and south-east periphery (Fig. 5). But in monsoon and postmonsoon seasons, the northern and central parts (the main built-up areas and bare lands of the city) were considered as the UHI zones. The UHI intensity for the whole of Raipur City was $2.54^{\circ} \mathrm{C}, 1.87^{\circ} \mathrm{C}, 1.76^{\circ} \mathrm{C}$, and $1.96^{\circ} \mathrm{C}$ in the premonsoon, monsoon, postmonsoon, and winter seasons, respectively. The mean LST values of the common UHI of the city in all four seasons
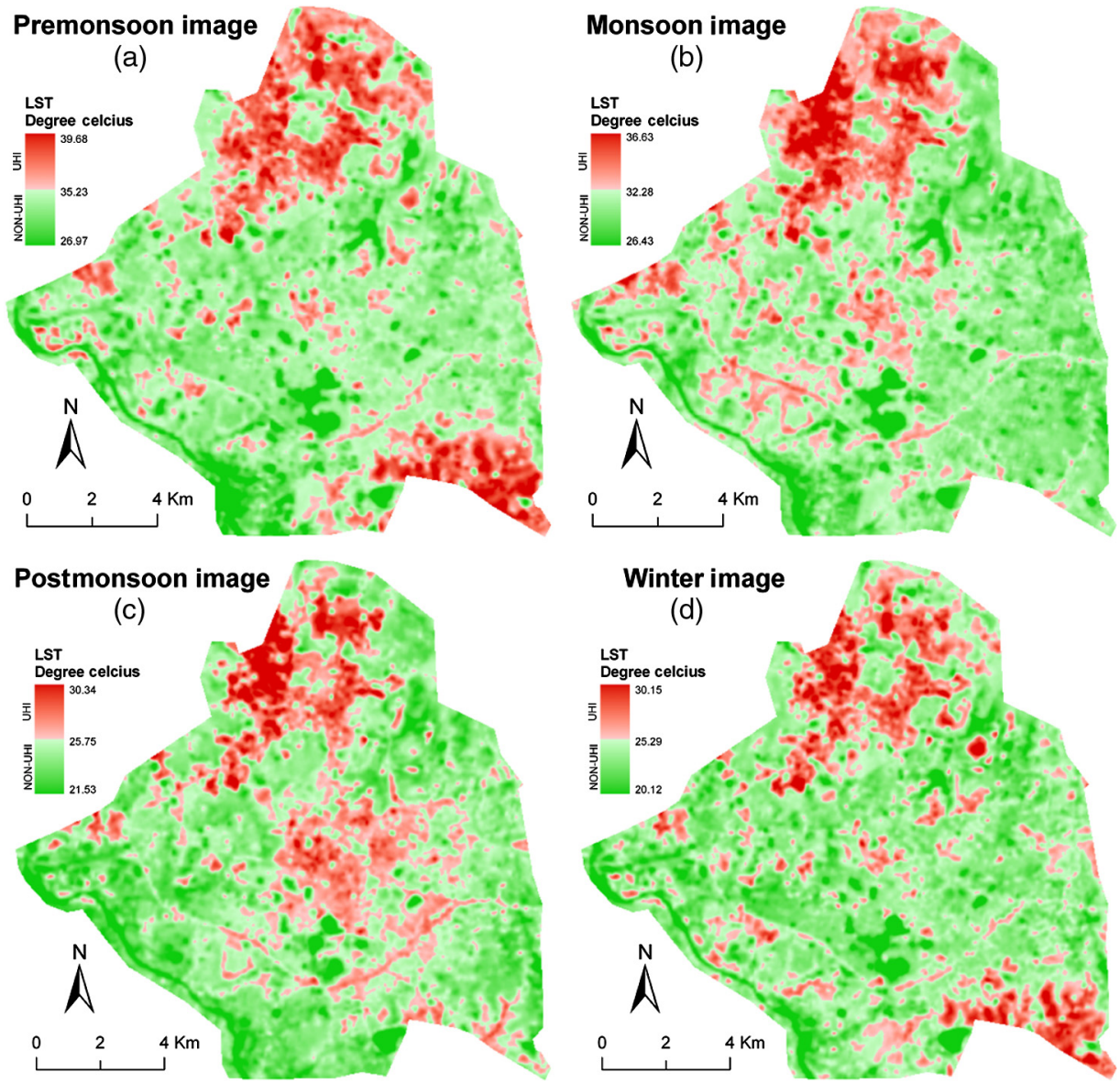

Fig. 5 Seasonal variations in UHI and non-UHI of Raipur City: (a) premonsoon, (b) monsoon, (c) postmonsoon, and (d) winter. 

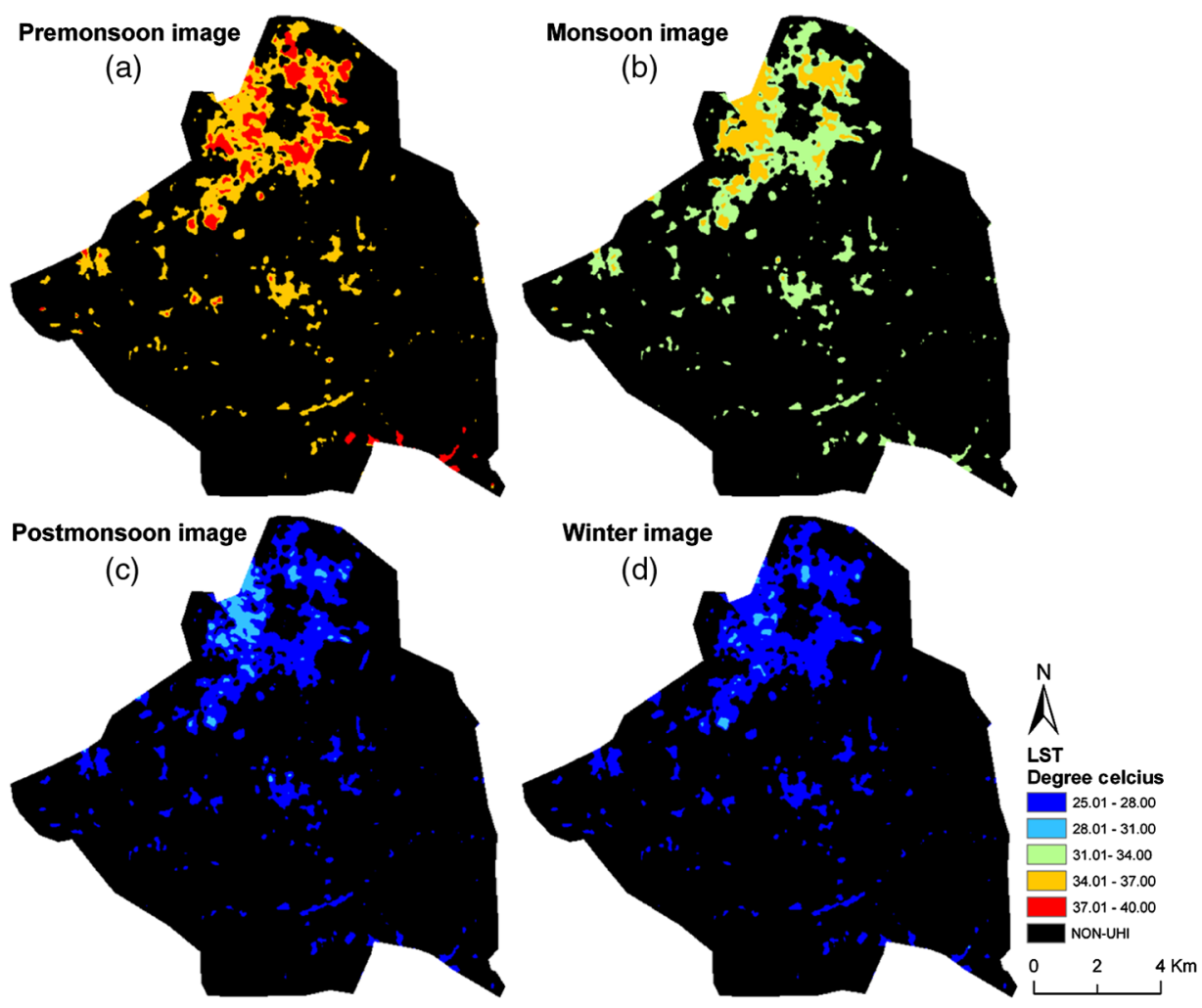

Fig. 6 Seasonal variations in common UHI of Raipur City: (a) premonsoon, (b) monsoon, (c) postmonsoon, and (d) winter.

were ranged between $26.45^{\circ} \mathrm{C}$ (winter image) and $36.51^{\circ} \mathrm{C}$ (premonsoon or summer image). Regardless of any particular season, the common UHI zones were developed mainly in the northwest portion (bare lands and built-up areas) of the city (Fig. 6).

\subsection{Relationship of LST with NDVI, NDWI, NDBI, and NMDI for the Whole Area, UHI, non-UHI, and Common UHI of Raipur City}

Generally, LST built negative relationships with NDVI and NMDI, whereas it built positive relationships with NDWI and NDBI. This particular pattern was seen in the whole of Raipur City, irrespective of dates (Table 7). NDBI and NMDI equally built strong regression with LST for four seasons. Their relationships became stronger in the premonsoon, monsoon, and postmonsoon seasons compared to winter. NDVI and NDWI showed weak relationships with LST compared to NDBI and NMDI. NDVI presented a slightly better relationship than NDWI. Winter season was the least reliable season for the relationships between LST and the four LULC indices. LST-NDWI relationship remained almost neutral in winter. This is partially due to the presence of high amount of dust particles in the air in winter.

But these relationships tend to be changed within the UHI of the city where NDVI and NDWI reflected a stronger regression with LST for all the four seasons (Table 7). Again, the scenario became different within the non-UHI portions of the city where NDBI and NMDI presented a stronger regression with LST compare to the other two spectral indices. In the common UHI region, NDVI and NDWI had a much better regression with LST, but these relationships became gradually weak with the increase of the heterogeneous surface features. Monsoon and postmonsoon images revealed a better regression of LST with NDVI and NDWI due to the higher percentage of water and vegetation.

In the UHI and common UHI, high LST values were found in such areas where NDVI values were low but NDWI values were high. NDWI showed the strongest positive regression with LST, whereas NDVI showed the strongest negative regression. The monsoon and postmonsoon season revealed the most consistent relationship. In the non-UHI, the high LST values were 
Table 7 Correlation coefficients for LST-NDVI, LST-NDWI, LST-NDBI, and LST-NMDI relationships.

\begin{tabular}{|c|c|c|c|c|}
\hline Season & LST-NDVI & LST-NDWI & LST-NDBI & LST-NMDI \\
\hline \multicolumn{5}{|l|}{ (Whole of Raipur City) } \\
\hline Premonsoon (mean) & -0.4235 & 0.2937 & 0.6984 & -0.6988 \\
\hline Monsoon (mean) & -0.4978 & 0.4123 & 0.4528 & -0.5291 \\
\hline Postmonsoon (mean) & -0.5124 & 0.4272 & 0.6239 & -0.6647 \\
\hline Winter (mean) & -0.1748 & 0.0414 & 0.5676 & -0.5509 \\
\hline \multicolumn{5}{|l|}{ (UHI of Raipur City) } \\
\hline Premonsoon (mean) & -0.3298 & 0.2609 & 0.2883 & -0.1622 \\
\hline Monsoon (mean) & -0.4998 & 0.5755 & -0.0850 & -0.0876 \\
\hline Postmonsoon (mean) & -0.4866 & 0.5144 & 0.0905 & -0.2367 \\
\hline Winter (mean) & -0.3104 & 0.2572 & 0.2213 & -0.3657 \\
\hline \multicolumn{5}{|c|}{ (Non-UHI of Raipur City) } \\
\hline Premonsoon (mean) & -0.2834 & 0.1234 & 0.6877 & -0.6553 \\
\hline Monsoon (mean) & -0.2608 & 0.0859 & 0.5437 & -0.5509 \\
\hline Postmonsoon (mean) & -0.2032 & 0.0822 & 0.5827 & -0.5637 \\
\hline Winter (mean) & 0.0141 & -0.1633 & 0.5497 & -0.4782 \\
\hline \multicolumn{5}{|c|}{ (Common UHI of Raipur City) } \\
\hline Premonsoon (mean) & -0.3591 & 0.3267 & 0.1759 & -0.2477 \\
\hline Monsoon (mean) & -0.5170 & 0.5908 & -0.1992 & 0.0183 \\
\hline Postmonsoon (mean) & -0.5607 & 0.5452 & 0.1579 & -0.3367 \\
\hline Winter (mean) & -0.3314 & 0.2726 & 0.0696 & -0.1892 \\
\hline
\end{tabular}

corresponding to high NDBI and low NMDI values. Due to the presence of more moisture content in soil and air, the relationships between LST and these spectral indices became more consistent in the monsoon and postmonsoon images. NDBI showed the strongest positive regression with LST, whereas NMDI showed the strongest negative regression. The premonsoon season reflected the most significant relationship.

The best regression between LST and the four spectral indices was found for the whole of Raipur City, irrespective of any date. This relationship became weaker with the increase in heterogeneity in an urban landscape. Common UHI of all seasons simply indicated the built-up area and semibare lands, which were more heterogeneous. Thus the least regression was found in the common UHI of the city area. UHI and non-UHI of the city reflected the moderate range of the correlation coefficient values.

\section{Conclusion}

In this paper, eleven Landsat 8 data of four different seasons in a single-year span were selected for analyzing the effect of UHI intensity in Raipur City of India and to interpret the seasonal variations for the relationships of NDVI, NDWI, NDBI, and NMDI with LST. The above relationships were examined for the whole area, UHI, non-UHI, and common UHI of the Raipur City. UHIs were identified through the spatial distribution of LST, which mainly existed in the northern and southern parts of the city. Generally, high LST values were generated in the bare 
land and built-up area. LST level was reduced significantly in the vegetal covered areas and water bodies.

Moreover, the relationships of LST to NDVI, NDWI, NDBI, and NMDI were analyzed using linear regression per-pixel level. In whole Raipur City, LST showed a strong positive regression with NDBI and a moderate to strong negative regression with NMDI, irrespective of any season. Inside the UHI, NDVI and NDWI showed a stronger regression (NDVI-negative and NDWIpositive) with LST in comparison with the other indices. Conversely, inside the non-UHI zone, NDBI and NMDI presented a stronger regression (NDBI-positive and NMDI-negative). Again, NDVI-LST and NDWI-LST regression became stronger within the common UHI in all seasons.

Another objective of the research was to estimate the variations in the regression analysis for the satellite images of four different seasons. Monsoon and postmonsoon seasons were more prominent in showing the regression between LST and spectral indices due to the higher percentage of healthy green vegetation and soil moisture. The premonsoon season was less dominant compared to the monsoon and postmonsoon seasons while this regression became weakest in the winter image.

\section{Acknowledgments}

The authors were indebted to the United States Geological Survey. ${ }^{36}$ The authors also thank the anonymous reviewers whose feedback improved this manuscript significantly.

\section{References}

1. J. Arnfield, "Two decades of urban climate research: a review of turbulence, exchanges of energy and water, and the urban heat island," Int. J. Climatol. 23(1), 1-26 (2003).

2. P. A. Mirzaei, "Recent challenges in modeling of urban heat island," Sustain. Cities Soc. 19, 200-206 (2015).

3. A. M. Rizwan et al., "A review on the generation, determination and mitigation of the urban heat island," J. Environ. Sci. 20(1), 120-128 (2008).

4. C. Rinner and M. Hussain, “Toronto's urban heat island exploring the relationship between land use and surface temperature," Remote Sens. 3, 1251-1265 (2011).

5. M. Zhao et al., "Influence of urban expansion on the urban heat island effect in Shanghai," Int. J. Geogr. Inf. Sci. 30(12), 2421-2441 (2016).

6. B. Chun and J.-M. Guldmann, "Spatial statistical analysis and simulation of the urban heat island in high-density central cities," Landsc. Urban Plann. 125, 76-88 (2014).

7. Z. Dai et al., "Spatial regression models of park and land-use impacts on the urban heat island in central Beijing," Sci. Total Environ. 626, 1136-1147 (2018).

8. J.-P. Kim and J.-M. Guldmann, "Land-use planning and the urban heat island," Environ. Plann. B 41, 1077-1099 (2014).

9. H. Zhang et al., "Analysis of land use/ land cover change, population shift, and their effects on spatiotemporal patterns of urban heat islands in metropolitan Shanghai, China," Appl. Geogr. 44, 121-133 (2013).

10. W. Q. Zhou et al., "Does spatial configuration matter? Understanding the effects of land cover pattern on land surface temperature in urban landscapes," Landsc. Urban Plan. 102(1), 54-63 (2011).

11. P. Coseo and L. Larsen, "How factors of land use/land cover, building configuration, and adjacent heat sources and sinks explain Urban Heat Islands in Chicago," Landsc. Urban Plann. 125, 117-129 (2014).

12. J. Li et al., "Impacts of landscape structure on surface urban heat islands: a case study of Shanghai, China," Remote Sens. Environ. 115, 3249-3263 (2011).

13. J. Peng et al., "Urban thermal environment dynamics and associated landscape pattern factors: a case study in the Beijing metropolitan region," Remote Sens. Environ. 173, 145-155 (2016).

14. R. Amiri et al., "Spatial-temporal dynamics of land surface temperature in relation to fractional vegetation cover and land use/ cover in the Tabriz urban area, Iran," Remote Sens. Environ. 113, 2606-2617 (2009). 
15. J. Song et al., "The relationships between landscape compositions and land surface temperature: quantifying their resolution sensitivity with spatial regression models," Landsc. Urban Plann. 123, 145-157 (2014).

16. W. Kuang et al., "What are hot and what are not in an urban landscape: quantifying and explaining the land surface temperature pattern in Beijing, China," Landsc. Ecol. 30, 357-373 (2015).

17. K. Deilami and M. Kamruzzaman, "Modelling the urban heat island effect of smart growth policy scenarios in Brisbane," Land Use Policy 64, 38-55 (2017).

18. S. Guha et al., "Dynamic analysis and ecological evaluation of urban heat islands in Raipur City, India," J. Appl. Remote Sens. 11(3), 036020 (2017).

19. Q. Nie et al., "Spatiotemporal impact of urban impervious surface on land surface temperature in Shanghai, China," Can. J. Remote Sens. 42(6), 680-689 (2016).

20. G. L. Feyisa et al., "Locally optimized separability enhancement indices for urban land cover mapping: exploring thermal environmental consequences of rapid urbanization in Addis Ababa, Ethiopia," Remote Sens. Environ. 175, 14-31. (2016).

21. J. M. R. Lopez et al., "Frontiers of urbanization: identifying and explaining urbanization hot spots in the south of Mexico City using human and remote sensing," Appl. Geogr. 79, 1-10 (2017).

22. H. Pearsall, "Staying cool in the compact city: vacant land and urban heating in Philadelphia, Pennsylvania," Appl. Geogr. 79, 84-92 (2017).

23. S. Guha et al., "Analytical study of land surface temperature with NDVI and NDBI using Landsat 8 OLI and TIRS data in Florence and Naples city, Italy," Eur. J. Remote Sens. 51(1), 667-678 (2018).

24. Y. Y. Cui and B. de Foy, "Seasonal variations of the urban heat island at the surface and the near-surface and reductions due to urban vegetation in Mexico City," J. Appl. Meteorol. Clim. 51, 855-868 (2012).

25. W. Zhou et al., "Relationships between land cover and the surface urban heat island: seasonal variability and effects of spatial and thematic resolution of land cover data on predicting land surface temperatures," Landsc. Ecol. 29, 153-167 (2014).

26. S. Haashemi et al., "Seasonal variations of the surface urban heat island in a semi-arid city," Remote Sens. 8, 352 (2016).

27. B. Chun and J. M. Guldmann, "Impact of greening on the urban heat island: seasonal variations and mitigation strategies," Comput. Environ. Urban Syst. 71, 165-176 (2018).

28. J. Peng et al., "Seasonal contrast of the dominant factors for spatial distribution of land surface temperature in urban areas," Remote Sens. Environ. 215, 255-267 (2018).

29. A. Mathew et al., "Investigating spatial and seasonal variations of urban heat island effect over Jaipur city and its relationship with vegetation, urbanization and elevation parameters," Sustain. Cities Soc. 35, 157-177 (2017).

30. J. Quan et al., "Time series decomposition of remotely sensed land surface temperature and investigation of trends and seasonal variations in surface urban heat islands," J. Geophys. Res-Atmos. 121(6), 2638-2657 (2016).

31. M. Khorchani et al., "Trends in LST over the peninsular Spain as derived from the AVHRR imagery data," Global. Planet. Change 166, 75-93 (2018).

32. M. Khorchani et al., "Average annual and seasonal land surface temperature, Spanish Peninsular," J. Maps. 14(2), 465-475 (2018).

33. R. Yao et al., "Interannual variations in surface urban heat island intensity and associated drivers in China," J. Environ. Manage. 222, 86-94 (2018).

34. J. Lai et al., "Does quality control matter? Surface urban heat island intensity variations estimated by satellite-derived land surface temperature products," ISPRS J. Photogramm. Remote Sens. 139, 212-227 (2018).

35 . R. Sun et al., "A landscape connectivity model to quantify contributions of heat sources and sinks in urban regions," Landsc. Urban Plann. 178, 43-50 (2018).

36. S. Khandelwal et al., "Assessment of land surface temperature variation due to change in elevation of area surrounding Jaipur, India," Egypt. J. Remote Sens. Space Sci. 21(1), 87-94 (2018). 
37. Q. Weng, "A remote sensing-GIS evaluation of urban expansion and its impact on surface temperature in Zhujiang Delta, China," Int. J. Remote Sens. 22(10), 1999-2014 (2001).

38. Q. Weng and S. Yang, "Managing the adverse thermal effects of urban development in a densely populated Chinese city," J. Environ. Manage. 70(2), 145-156 (2004).

39. Z. Zhang et al., "Towards an operational method for land surface temperature retrieval from Landsat 8 data," Remote Sens. Lett. 7(3), 279-288 (2016).

40. Z. Qin et al., "A mono-window algorithm for retrieving land surface temperature from Landsat TM data and its application to the Israel-Egypt border region," Int. J. Remote Sens. 22(18), 3719-3746 (2001).

41. Z.-L. Li et al., "Satellite-derived land surface temperature: current status and perspectives," Remote Sens. Environ. 131, 14-37 (2013).

42. J. C. Munoz and J. A. Sobrino, "A generalized single channel method for retrieving land surface temperature from remote sensing data," J. Geophys. Res. 108(D22), 4688 (2003).

43. J. C. Munoz et al., "Revision of the single-channel algorithm for land surface temperature retrieval from Landsat thermal-infrared data," IEEE Trans. Geosci. Remote Sens. 47(1), 339-349 (2009).

44. J. C. Munoz and J. A. Sobrino, "A single-channel algorithm for land-surface temperature retrieval from ASTER data," IEEE Geosci. Remote Sens. Lett. 7(1), 176-179 (2010).

45. X. Yu et al., "Land surface temperature retrieval from Landsat 8 TIRS-comparison between radiative transfer equation-based method, split window algorithm and single channel method," Remote Sens. 6, 9829-9852 (2014).

46. O. Rozenstein et al., "Derivation of Land Surface Temperature for Landsat-8 TIRS Using a Split Window Algorithm," Sensors 14(4), 5768-5780 (2014).

47. Z. Qin et al., "Derivation of split window algorithm and its sensitivity analysis for retrieving land surface temperature from NOAA-advanced very high resolution radiometer data," J. Geophys. Res. 106(D19), 22655-22670 (2001).

48. A. Bendib et al., "Contribution of Landsat 8 data for the estimation of land surface temperature in Batna city, Eastern Algeria," Geocarto Int. 32(5), 503-513 (2016).

49. Staff Reporter, RAIPUR, "Raipur beats Indore, Bhopal in ease of living index," https://www .dailypioneer.com/2018/state-editions/raipur-beats-indore-bhopal-in-ease-of-living-index .html (accessed 14 August 2018).

50. EarthExplorer, "Home-United States Geological Survey," http://earthexplorer.USGS.gov.

51. T. S. Purevdorj et al., "Relationships between percent vegetation cover and vegetation indices," Int. J. Remote Sens. 19 (18), 3519-3535 (1998).

52. C. Gao, "NDWI-a normalized difference water index for remote sensing of vegetation liquid water from space," Remote Sens. Environ. 58(3), 257-266 (1996).

53. Y. Zha et al., "Use of normalized difference built-up index in automatically mapping urban areas from TM imagery," Int. J. Remote Sens. 24(3), 583-594 (2003).

54. L. Wang and J. J. Qu, "NMDI: a normalized multi-band drought index for monitoring soiland vegetation moisture with satellite remote sensing," Geophys. Res. Lett. 34(20), L20405 (2007).

55. X. C. Chen et al., "Remote sensing image-based analysis of the relationship between urban heat island and land use/cover changes," Remote Sens. Environ. 104(2), 133-146 (2006).

56. B. L. Markham and J. K. Barker, "Spectral characteristics of the LANDSAT thematic mapper sensors," Int. J. Remote Sens. 6(5), 697-716 (1985).

57. G. E. Wukelic et al., "Radiometric calibration of Landsat thematic mapper thermal band," Remote Sens. Environ. 28, 339-347 (1989).

58. J. A. Sobrino et al., "Land surface temperature retrieval from Landsat TM 5," Remote Sens. Environ. 90, 434-440 (2004).

59. J. A. Sobrino et al., "A comparative study of land surface emissivity retrieval from NOAA data," Remote Sens. Environ. 75(2), 256-266 (2001).

60. T. N. Carlson and D. A. Ripley, "On the relation between NDVI, fractional vegetation cover, and leaf area index," Remote Sens. Environ. 62, 241-252 (1997).

61. J. Li, "Estimating land surface temperature from Landsat-5 TM," Remote Sens. Technol. Appl. 21(4), 322-326 (2006). 
62. Q. Sun et al., "An ERDAS image processing method for retrieving LST and describing urban heat evolution: a case study in the Pearl River Delta Region in South China," Environ. Earth Sci. 59, 1047-1055 (2010).

63. Z. Wan and Z. L. Li, "MODIS land surface temperature and emissivity," in Land Remote Sensing and Global Environmental Change NASA's Earth Observing System and the Science of ASTER and MODIS, B. Ramachandran, C. O. Justice, and M. J. Abrams, Eds., Springer-Verlag, Heidelberg, New York, p. 567 (2011).

64. L. Yang et al., "Land surface temperature retrieval for arid regions based on Landsat-8 TIRS data: a case study in Shihezi, Northwest China," J. Arid Land. 6, 704-716 (2014).

Subhanil Guha received his MSc degree in geography from the University of Calcutta, India, and his postgraduate diploma degree in geoinformatics from the International Institute for Geo-Information Science and Earth Observation (ITC), Enschede, The Netherlands, and IIRS, Dehradun, India. He is pursuing his PhD in the Department of Applied Geology, National Institute of Technology (NIT), Raipur, India. His research interests include applications of thermal infrared remote sensing in geography, environment, and geology.

Himanshu Govil received his MSc and $\mathrm{PhD}$ degrees in geology from Aligarh Muslim University, Aligarh, India, and his postgraduate diploma degree in geoinformatics from the ITC, Enschede, The Netherlands, and IIRS, Dehradun, India. Currently, he is an assistant professor in the Department of Applied Geology, NIT, Raipur, India. His research interests include application of hyperspectral remote sensing in mineral exploration and geological mapping.

Prabhat Diwan received his MTech and PhD degrees in geology from Dr. Harisingh Gour University, Sagar, India. Currently, he is an associate professor and a head of the Department of Applied Geology, NIT, Raipur, India. His research interests include structural geology, economic geology, and remote sensing. 